\title{
Speech aggression as a manifestation of dominance: pragmalinguistic aspects
}

\author{
Lidia Novikova $^{1}$ and Fotina Shuraeva ${ }^{1, *}$ \\ ${ }^{1}$ Don State Technical University, Gagarin square, 1, Rostov-on-Don, 344000, Russia
}

\begin{abstract}
The authors investigate the phenomenon of speech aggression in texts of various directions. The destruction of the cultural system, built exclusively on religious unity, marks the end of the Middle Ages, coming towards the end of the fourteenth century. It was then that the formation of a new principle begins, which is that "objective reality and its meaning are sensual. Reality is comprehended not with the help of revelation, transposed by selected religious practices, but through the senses. The role of anthropocentrism is growing both at the philosophical and cultural, and at the speech-thinking (linguo-cognitive) levels. A cultural system based on such a premise idealistic. In it, feeling is balanced by intellect, faith by science, empirical perception by intuition. Its values belong to both the Earth and Heaven. Her world is both sensual and supersensible.
\end{abstract}

\section{Introduction}

The texts of this period can still be divided into artistic-journalistic, religious and officialbusiness. But in them centripetal forces are already beginning to form, dividing them into independent units. For example, "The Life of Sergius of Radonezh" by E. the Wise is to the same extent a publicistic work as a purely literary and religious one. As in the religious journalism of the XII-XIII centuries, a portrait of an ideal person is given, who possessed all the necessary qualities inherent in a Christian. It is explained in detail and popularly what a person should be on the example of a person known in the general Russian religious environment.

The specificity of journalism of the XIV century is largely determined by the political and ideological struggle caused by the formation of a single state and the first religious contradictions in Russian Orthodoxy [1]. In this regard, the authors of works conceptualize their own ideals to a greater extent, relying not so much on a generalized tradition as on personal beliefs and understanding of the essence of the processes taking place.

Reconstruction of the speech personality of this period involves operating with monuments belonging to specifically identified persons, and therefore, should take into account even more the presence of individual and personal characteristics of the style. Nevertheless, the analysis of the frequency use of lexemes of a continuous array of texts and their structural and semantic relationships within the conceptualized semantic groups (fields) allows us to specify the main features inherent in all authors as typical PERSONALITY of

\footnotetext{
*Corresponding author: georgy-2583@yandex.ru
} 
their era. Thus, it is possible to identify the key features of the lexical-semantic level speech personality of the XIV-XV centuries. and compare them with similar features of the previous period $[2,3]$.

As before, the basis of the vocabulary of journalistic and artistic journalistic texts is formed by the words indicating and naming, but the frequency of their use is much higher [1].

\section{Materials and methods}

"Indicating words" (pronouns) in the author's lexicon make up about 10\% of the entire set of lexemes, in some texts reaching 15\% (for example, in the "Epistles" of Elder Philotheus), which is explained by their genre specificity and context.

Within the framework of a fairly extensive lexico-grammatical group of "naming words" in the speech personality lexicon, nouns and various substantive forms are highlighted, in second place, as before, are verbs. The total number of nouns increases to $71 \%$ of the total number of words in the lexicon. The number of uses of proper names and topographic names is increasing, the number of names for tools of labor, military equipment, etc. is decreasing. There is some terminological confusion in terms related to professional and everyday vocabulary, which was not typical for the previous period. Probably, this can be considered a consequence of the deepening specialization and professionalization in the culture and language of Ancient Rus, when the class of "scribes" became somewhat isolated in the social environment and ceased to directly participate in agricultural and military activities, focusing on ideological work [4-6].

Verbs and verb forms are also distributed according to the subsets "being", "intellectual activity", "interaction (relations)", "movement in space".

Reconstruction of the conceptual (semantic) fields of the texts of public discourse makes it possible to highlight the semantic fields associated with various concepts.

The difference between perfect concepts and similar concepts of the early period is noticeable. Thus, the concept "God" no longer needs to be approved and the vocabulary associated with it is harmoniously distributed among other concepts, although it is fully preserved in circulation.

The first highlighted concept - "Righteous Life" - is positioned already from a slightly different position, which implies not only following Christian precepts, but the specifics of the normative Orthodox movement as opposed to heresies, therefore its semantic field contains antonymic parallelisms that have internal structural links between specific units. The field of the concept itself can be viewed in unity with the field "Fight against heresy". The lexicon speech personality within this field contains lexemes: blessed, piety, church, Most Holy Theotokos, $($ Virgin $)$ Mary, $\sin$, lord $=$ prince $=$ father $/$ Father in Heaven, create $=$ create = create, prophet, show mercy, have mercy, (by mercy, God's / God's providence) flock, Holy Spirit, beloved fathers and brothers, divine spiritual love, prayer. It is important to note that this concept includes vocabulary that was previously included in the concept of "God", which indicates a certain combination of these concepts "God" = "Righteous life" in the perception and linguo-cognitive practice speech personality. On the other hand, the concept leaves the traditional lexemes that reveal the concept of heaven, hell, and lexemes that reinforce these images, although the nomens denoting the main concepts remain. For example, in the texts there are almost no archangels hail, angelic garden, fetid abyss, etc. , which was typical for the XI-XIII centuries. The core of the field includes the words: spirit (meaning soul), life, death; alive; live - as tokens associated with the expression of the general field value. The center of the field is represented by the lexemes God, the universe, the soul, the world (universe), existence, the Creator; rebirth from the dead, as well as vocabulary denoting a religious rank: bishop, patriarch / patriarch, saint [7-9]. 
Antagonistic parallels are represented by the ranks of brother-enemy, sin-grace, heresygrace, decency-heresy, lie-grace, lie-god. Thus, the main communicative strategy of persuasion is revealed - the creation of antagonistic parallels, which at the intuitivestereotypical level forms the point of view of the recipient necessary for the rhetorician.

The concept of "Religious feat" almost does not receive a significant transformation, but its nuclear zone includes lexemes associated with the activities of secular persons and religious leaders who are not saints. For example, a prince, a bishop, monasticism. In the texts, these lexemes are included in a context emphasizing that their religious exploit began before they received grace from above, and that it was through their labor that they deserved this grace.

The concept of "Struggle against heresy" is gradually coming to the fore, although it will manifest itself most sharply in the later era, this problem is somehow present in many texts, even not directly related to the approval of religious doctrine. The core of this concept is the concept of heresy, represented by the lexemes heresy, sin of heresy, sin of apostate, blasphemer (heretic) $\backslash$ blasphemy (heresy). The lexemes are concentrated in the center: grace, truth, falsehood (falsehood), wisdom (in the meanings of "human wisdom" and "divine wisdom"), revelation (in the meanings of "revelation" and "truth" itself), delusion, blindness (delusion). In addition, verbs with the meaning of true and false speech, false teaching, deception as a process are concentrated in the center of the field $[10,11]$.

The concepts of "Statehood", "Law" and "Tsar" in journalism are significantly converging and reaching the dominant level. The core zones of the semantic fields are isolated, then, as their periphery intersects, forming a single lexico-semantic space. The problem of creating statehood, the concentration of monopolar power, personified by the king, is in the center of attention, which is reflected, among other things, at the lexical and semantic level. The core of the field "Statehood" is made up of the words country (in the meaning of the state), Moscow, Tver, Vladimir, Kiev (in the meaning of the state and state centers), law (in the meaning of power), power. The core of the "Law" field is made up of the lexemes law, power, law, word (meaning a way of control), gift, justice and retribution (as a rule, they always go in pairs), freedom. Those. it is possible to observe a change in the composition of the nuclear field of the field in comparison with a similar concept of the previous period, when the law was understood, first of all, as a religious dogma that determines the norm of being and society [12-15].

\section{Discussion}

The core of the concept "Tsar" is made up of lexemes tsar, prince, sovereign with the same meaning "supreme power / supreme ruler". In the near-nuclear zone, there are lexemes power, law and law, law (in the meaning of justice), deed, destiny and purpose. On the periphery of the concepts there are such lexemes as business, know (upper class), craft (thinking, rational activity), power (meaning opportunity), piety, judge (as a synonym for king - may be in the core of the field), desire, opportunity, deed, justice and unrighteous judgment, grace, striving, beginning (in a religious sense, as the starting point of the actions of incentive forces).

In general, the lexical composition of the speech personality lexicon of this time is more variegated and diverse. The genre specificity of the produced text, which determines the strategy and the choice of lexical units, has a much more pronounced effect; tendencies towards the creation of purely sociopublicistic genres, distanced from artistic and religious ones, begin to appear. Epistolary genres begin to play a special role here, representing a representation in public discourse of personal correspondence on socially significant issues. The formed genre of "Messages" allows you to enter into the communicative environment of the text of the reader as an active figure, personify him as a personal addressee. This, in turn, reflects a certain change in the specificity of the vocabulary, in which one can observe the 
dominance of personal appeals, references to the intelligent activity of the interlocutor, the highlighting of portrait features, which was uncharacteristic for the previous period and was little represented in the lexicon SPEECH PERSONALITY in public discourse XI-XIII centuries To confirm this hypothesis, we turn to the texts of personal correspondence reflected in a large number of birch bark letters studied by Academician A.N. Zaliznyak and other researchers. Among the features of the lexicon of the authors of the epistles of the XIXIII centuries. scholars note a high degree of personification of the addressee and addressee, a direct appeal to the person, an indication of its specific features or actions that are important for the author of the messages. Personal correspondence has a certain psychologism and conveys a living portrait of a contemporary. Now all this is observed in messages formally addressed to an individual, but in fact to society. Thus, the tendencies previously manifested in personal correspondence began to dominate in the journalistic genre as a conscious means of influence, which presupposes a purposeful selection of lexical-semantic and stylistic means, i.e. conscious perception of the possibilities of influence of the lexicon speech personality of this period.

\section{Results}

The author of publicistic texts acts mainly not as a religious propagandist, but as a political and public figure, forming a state, including a religious, idea.

The conglomerate of texts of official business appeal is still represented by texts of natural science and educational content and legal documents. However, the lexical composition of these texts changes significantly. The texts of natural science content are imbued with the desire for a general ideological orientation - the positioning of a centralized state, as well as the dissemination of scientific, in the exact meaning of the word, knowledge. The mythological content is gradually disappearing from them. Even Christian mythology takes on the character of a cliché, a traditional formula replacing knowledge that is unknown or unproven by science. In general, the old concepts remain

At the same time, the concepts "Natural Science", "Exact and Natural Sciences", "Jurisprudence", "Life and Way" are already clearly structured, terminologized and have coincidences only on the periphery of the fields.

"Natural science" preserves the core of the world, country, land (in the sense of locality), place. In the nuclear area there are the names of birds, animals, trees, the number of which increases to 1200 units, some of which are synonyms and variants. On the periphery, there are lexemes denoting the geographical distribution of animals, people and events constantly associated with their existence, habitat. It is important to note that there were probably much more names for living beings and related phenomena before, but they were not included in public discourse, due to their everyday use, not principled for the general idea of religious unity of the Eastern Slavs. The gravitation towards a realistic perception of reality, everyday life in everyday life, was reflected in the inclusion in circulation of a larger volume of nominative and terminological vocabulary.

The categories "Exact and natural sciences", "Life and way of life" are presented by structured groups, in the nuclear zone of which, there are basic terms and nomens that define the essence of economic and scientific research activities of a person. At the same time, a high degree of dialectal representation of this "terminology" is preserved, when the same concept can be conveyed by different words associated with the locality from which the author of the text comes.

A special place in this period is occupied by texts of a legal nature. It is during this period of time that the speech personality acquires the specification for the author - publicist ("scribe") and author-lawyer, fundamentally differing in vocabulary, perception and representation of the linguistic picture of the world. 
The very fact of the emergence of a strong centralized state in the north-east of Russia contributed to the development of such a kind of Russian written language as the business state language of the Moscow principality (more precisely, the Grand Duchy of Vladimir and Moscow). The lexicon speech personality of the author of the legal text to a certain extent goes back to the lexicon of the 11th-13th centuries, however, in general, the business language of the Moscow state cannot be derived as a pure continuation of the business language of the most ancient period. We believe that it developed on the basis of the living Moscow dialect of the XIV-XV centuries. and later period. The language of the Moscow state from the very beginning acquired a national character and a significant degree of processing and normalization. Structurally, it is opposed to both the bookish Church Slavonic and, to a large extent, the local dialects of business writing, reflecting the specifics of the language of feudal Russia. The centralization of the state, even in the absence of national ties as such, determined the dominance of the Moscow norm of the business language over dialectal tendencies in writing, as a result, by the 16th century. the Moscow "command" language is being transformed into a single national language of the state. ...

The ordering of the speech personality lexicon allows you to structure it and reveal other tendencies and features than those that were in the lexicon of the previous period. State letters and other monuments of business writing record the appearance in the language of new lexemes that are not known to the language of previous historical periods.

New concepts are being formed, associated primarily with social changes in society.

Concept "Estate". The core of the names of the estates with their purely legal interpretation: tsar, prince, bolyarin / boyar, city dweller, resident (in the sense of a city dweller), peasant, etc. In the center of the field are the concepts of class duties and rights: to serve, pakhati (as a duty), ratovati (defend, fight), etc. On the periphery, there are lexemes associated with the concepts of the result of class activity, state structure, etc.: fatherland, otchinnik, law, rule (in the sense of straightening, creating a person for public service), etc. It is important to note that the concept of "Estates" is almost entirely related to the concepts of civil service and legal and regulatory interaction between the inhabitants of the state, private relations are almost not represented in it.

Concept "Profession". Core: Ortai, Plowman, Howl, Shooter / Sagittarius, Gunner, Goldsmith, etc. In the center of the field there are related concepts that are also included in the field "Life and way of life" - arable land, hut, sowing, pasturing, etc. On the periphery, there are lexemes with the meaning of working conditions, the characteristics of a particular profession: fire (shoot), harvest (harvest), the periphery of this semantic field intersects with similar fields "Estate" and "Commodity-money relations".

Concept "Commodity-money relations". The core of money, altyn, bill of sale, etc. In the center of the field are the processes associated with transactions and making a profit: trading, walking (meaning to move goods), etc. On the periphery, there are lexemes with the meaning of the conditions of activity, legal subtleties and conventions.

A special place is occupied by the concept of "Public service", which can be divided into two minifields, united by a common core, represented by lexemes state, service, order, deed, clerk, clerk, order, rule (execute, serve), letter (document).

The first minifield concerns domestic affairs, primarily tax and judicial practice. In the center are lexemes: litigation, tax, vira (archaism), tax (tax), etc.

The second minifield concerns foreign policy. In the center of the lexeme: ambassador,

In business speech, the selection of linguistic means from living speech occurs, due to the presence of connections between the written command language and certain literary traditions. It is important to note that the SPEECH PERSONALITY of a public figure in this case is not differentiated according to the principle of professional belonging to public and non-public figures. The functionality of public communication implies belonging to the professional class of civil servants of orders, and the command language, thus, has a wider 
functionality than the modern narrow-profile office. As a result, literary (book) elements are widely used in the texts of official documents, which have the purpose of a stencil, an official style formula: inceptions or endings used in various types of letters; for example, in $\mathrm{x}$ "spiritual letters" - to "with your belly, with your whole mind", the canonical "in the name of the father, son and holy spirit", etc. It is important to note that the speech personality of a public figure presupposed a clear stylistic differentiation of vernacular, used in everyday personal and business correspondence, not related to the range of legal documents (reference and notification and narrowly administrative correspondence), and a socially significant style of official documents. At the same time, the book vocabulary acted both as a stylistic differential (for example, Old Slavicism hail as a mandatory attribute of official letters), and as termininoids, denoting concepts for which there were no options in everyday Great Russian vocabulary.

The speech personality of a public figure was distinguished not only by the ability to differentiate the style of presentation of official and unofficial papers, but also by internal, narrowly specific differentiation within the official style. So, at the lexical-semantic and stylistic levels, the dependence of the division of letters according to their content-stylistic model is clearly traced. The letters of religious and spiritual content more than others gravitate towards the book style, they have an obvious dependence on the Old Slavonic language of religious literature, a formal connection with religious tradition.

Diplomas of an everyday or professional nature (for example, certificates of gratitude) are more free in their style and to a greater extent reflect the everyday side of the linguistic picture of the world in the mind of the speech personality.

Modeling the linguistic processes of that period, we can get the speech personality of a contemporary, clearly differentiating the generated text (and, probably, public speech) according to internal substantive criteria, choosing a style of presentation depending, first of all, on the content of the document. It is important to note that addressing to a collective or individual communicator in a given period of time does not play a special role and the speech personality of a public figure interacts with the ideal speech personality of a contemporary. A special selection of linguistic means is determined primarily by the significance of the text, and not by the peculiarities of its perception.

If in business letters that had a private legal character, there were certain fluctuations associated with the personality of the author of the document, his personal distinction between the style of everyday and business communication, then in large documents the speech personality of the author was maximally leveled, and the language was brought to perfect, in the conditions of that time, uniformity.

Comparing the vocabulary of the public speech personality of two periods of time, it is possible to observe the dynamics of its changes. Speech personality XIV-XV centuries differs significantly from the speech personality of the previous period. At the lexico-semantic level, there is a deepening of the differences between the rhetorical images of a publicist (scribe) and a clerk. At the same time, journalism begins to form as a purely secular direction of literature, distancing itself from fiction and homiletics.

At the verbal level, this is reflected in the change in key ideological concepts that consolidate the lexical base of the speech personality and make up its picture of the world. Vocabulary speech personality is distinguished by significant richness and diversity. The total volume of lexical units, including names, terms, variants and synonyms, is about 7000 words. The average content of the text ranges from 700 to 2000 words, fictional and journalistic texts can reach 10,000 words. Publicistic texts are quite emotive, have pronounced signs of targeted rhetorical training, and fully reveal the intention and strategy of persuasion. 


\section{Conclusion}

Compared to the previous era, the texts of the official business style acquire some emotiveness, although not the same as the artistic and religious-journalistic ones, they are still informative, practically devoid of evaluativeness, although in some cases they may contain an important conclusion for the author.

The typological volume of the lexicon speech personality can be represented in the form of a diagram 1 (fig. 1 )

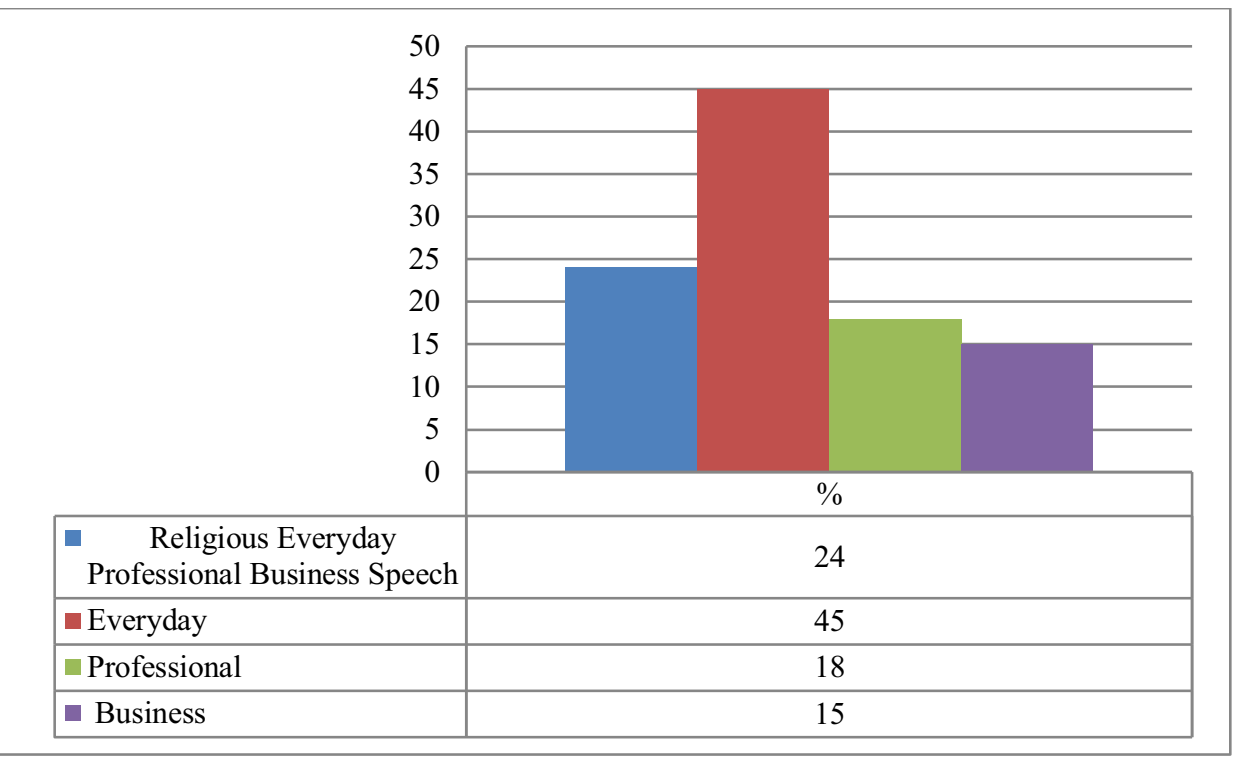

Fig. 1. The percentage of vocabulary in the lexicon of the speech personality of the XIV-XV centuries (development of the authors).

The percentage of professional vocabulary used in public discourse is increasing and will continue to grow until the end of the 18th century, when professional vocabulary will begin to be supplanted from publicistic texts. However, it should be noted that already in this period, there is a lack of distinction by authors-publicists of some terms and professional concepts, a desire to replace the factual side of descriptions with rhetorical means of expressiveness and persuasion.

\section{References}

1. N.J. Albury, Crit. Inq. Lang. Stud. 12(4), 256-282 (2015) doi:10.1080/15427587.2015.1096732

2. D.S. Anderson, Lang. Educ. 25(4), 273-289 (2011) doi:10.1080/09500782.2011.577218

3. M. De Meulder, A. Kusters, E. Moriarty, J.J. Murray, J. Multiling, Multicult. Dev. 2(2), 1-15 (2019) doi:10.1080/01434632.2019.1592181

4. P. Garrett, Attitudes to Language (Cambridge, 2011) doi:10.1017/CBO9780511844713

5. K.A. King, M. Hermes Lang, Ident. Educ. 13(4), 268-282 (2014) doi: $10.1080 / 15348458.2014 .939029$

6. A. Kusters, Lang. Soc. 43(2), 139-158 (2014) doi:10.1017/S0047404514000013 
7. A. Kusters, M. Spotti, R. Swanwick, E. Tapio, Int. J. Multiling. 14(3), 219-232 (2017) doi:10.1080/14790718.2017.1321651

8. J. Safar, Appl. Ling. Rev. (2017) doi: 10.1515/applirev-2017-0082

9. J. Safar, O. Le Guen, G. Collí Collí, M. Collí Hau, Sign Lang. Stud. 18(4), 488-516 (2018) doi:10.1353/sls.2018.0014

10. J. Sallabank, Multilingua 38, (2018) doi: 10.1515/multi-2018-0002

11. T.B. Mikheeva, E.V. Murugova, SHS Web of Conf. (2019) doi.org/10.1051/shsconf/20197007003

12. S.V. Pervukhina, O.A. Evtouchenk., L.Iu. Kotliarenko, M.P. Churikov, SHS Web of Conferences, Curr. Iss. Mod. Ling. Hum., 232-244 (2020) doi: $10.1051 /$ shsconf $/ 20208801013$

13. M.A. Tamarkin, A.N. Isaev, E.V. Murugova, V.I. Butenko, MATEC Web of Conf. (2018) doi:10.1051/matecconf/201822601025

14. S. Pervukhina, V. Demchenko, E3S Web of Conf. 18033 (2020) doi:10.1051/e3sconf/202021018033

15. N.B. Boeva-Omelechko, M.R. Zheltukhina, O.P. Ryabko, G.G. Matveeva, E.V. Murugova, I.A. Zyubina, Space and Culture, India 4, 112-121 (2018) doi: 10.20896/saci.v6i4.387 